\title{
Negotiating roles, identities and pedagogical practice
}

\author{
Patricia Ong (University of Waikato)
}

\begin{abstract}
:
The paper is based on critical theory and ethnographic approaches that examine the influences on teaching practice and the development of professional identities. Constructed from the model from Goodwin's domains of influences from teachers' beliefs, knowledge and practices on pedagogical practice, the revised model is elaborated to integrate an interactive relationship between these domains and that of practice and professional identities. A postmodernist lens is used so that professional identities and leadership roles may be seen to be multiple, changing, conflicting and tenuous and involving the process of reflexivity, agency and performativity.
\end{abstract}

Key words: ethnographic approaches, teacher education, professional identities, pedagogical practice, postmodernist lens

\section{Introduction}

Postmodernism has been described through a multiplicity of perspectives [1] However, put simply, the term 'Postmodernism' may be described to have two broad possible meanings, both with reference to modernism. It has been used in aesthetic terms to refer to an epoch of arts development that comes after or in reaction to modernism. The alternative interpretation or meaning to the term 'Postmodernism' is used in a more philosophical sense to refer to an ethos often referred to as 'the postmodern'. The reference to 'the postmodern' represents a fundamental shift in the values and practices on which modernity is based, or a transformation of modernity.

Peters and Lankshear (2001) refers to the postmodern condition as represented by a cluster of philosophical concepts; anti-foundational, anti-naïve realism with a critique of binarism, antiessentialism through the cultural construction of subjectivity, with the removal of boundaries between literature and philosophy with the consequence of interdisciplinary and multidisciplinary blending. The key question posed in this paper is 'What are the domains of influences impacting professional practice and identities' More specifically, how does a postmodernist perspective enable us to better understand this relationship.

\section{The Postmodernist Curriculum}

Postmodernism offers a possible theoretical paradigm for exploring curriculum development and reform. There are a few conceptual ideas on the differences between 'modernism' and 'postmodernism'. While modernism is viewed as a closed system, postmodernism may be seen as an open system, allowing influx and exchange that enables transformation and change [2], [3]. This change is seen as not only transformative but also involves instability and uncertainty. The trends and shifts towards interdisciplinary, multidisciplinary and experiential approaches to teaching and learning in education can be seen as part of the reform and transformation of the postmodern curriculum [4].

In the context of globalization and with the influx of internationalized approaches and ideas, the postmodern curriculum may be viewed as dynamic and transforming, shaped by not only dominant discourses but also other lesser influences. This brings about the awareness and understanding that cultural meaning is socially constructed and fluid. The idea of cultural and pedagogical hybridity has been discussed in several contexts [5], [6]. 
The assumption is often made that the teacher-educator can enact culturally responsive pedagogies that acknowledge and validate all cultures alike. This assumption causes educators to presume that the practices they engage with in their educational settings are culturally universal [7]. This ignores the reality that there is a plurality of 'truth'. Postmodern curriculum theory challenges this universal hegemonic assumption of dominance by western cultures and seeks equal inclusion of minorities and marginalized cultures. Te Whariki, the bicultural curriculum framework in New Zealand for ECE is an excellent example of a curriculum that may be interpreted as postmodern as it empowers marginalized and indigenous groups to have a voice and extend beyond predefined and essentialized identities and cultural representations [7], [8].

\section{Navigating Practice and the Curriculum}

Using a model adapted from Goodwin's (2010) domains of teacher's beliefs, knowledge and experiences, Figure 1 outlines a model that can be used to expound the negotiating of practice based on this open system that allows the dynamic exchange and interaction of factors and influences on pedagogical practice and also professional identities [8], [10]. While independent factors such as family, cultural backgrounds and unique life experiences may be fixed and ingrained within an individual's blueprint, other variable factors are fluid, dynamic and shifting. These more fluid factors such as those found in the contextual, social and sociological domains may be changing and also impacted in return by pedagogical practice and developing professional identities.

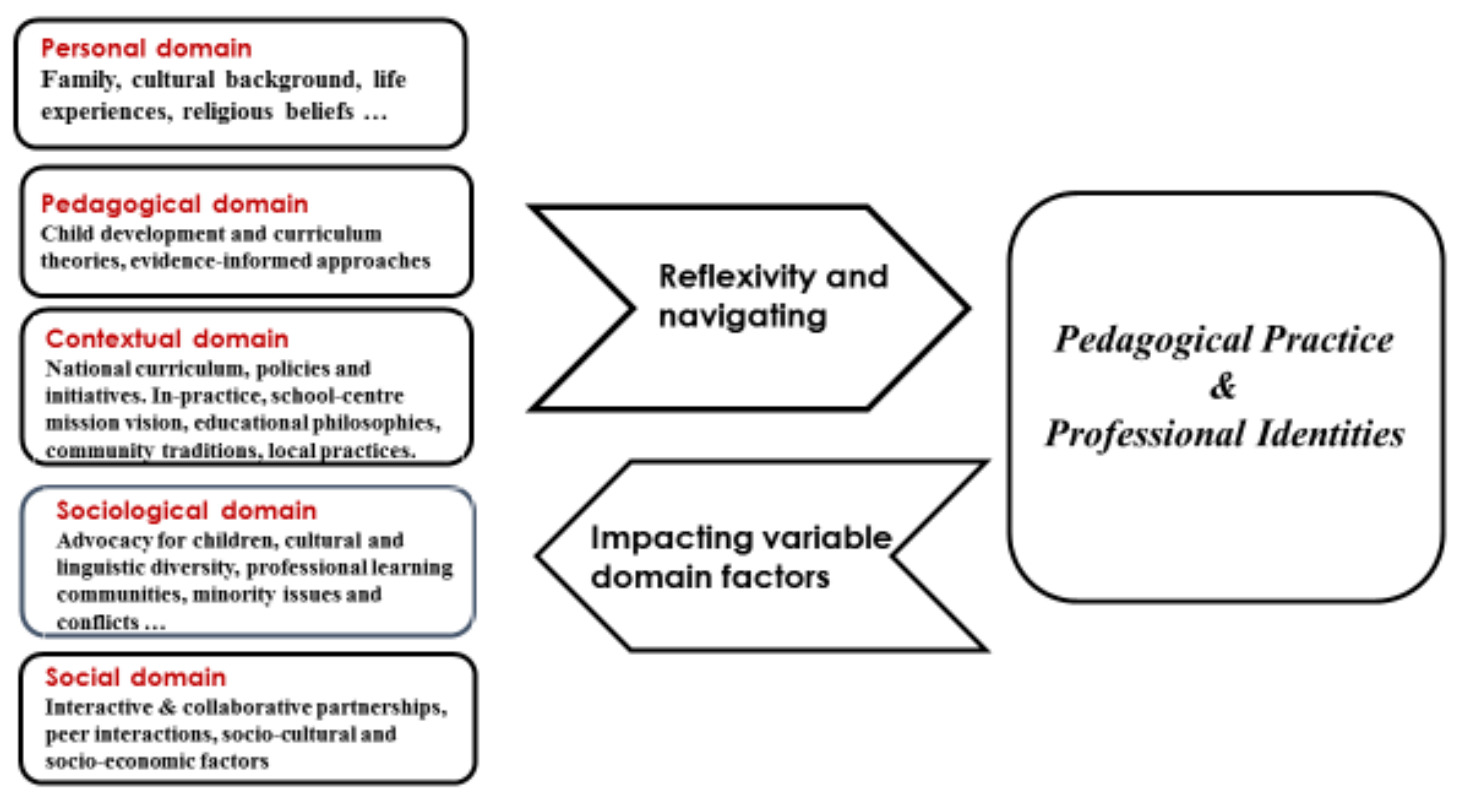

Figure 1: Domains of influence on Pedagogical Practice and Professional Identities

There is a spectrum of pedagogies detailed in research literature that acknowledges the diversity within various community contexts. These include culturally responsive [11], culturally relevant [12], [13], critical [14] and inclusive [15] pedagogies. The range of these approaches acknowledges the complexity, uncertainty and even confusion of the process of generating and navigating pedagogical practice in different cultural and community contexts [7].

This brings us to the use of postmodernism in re-defining identities and roles of educator and learner in the educational setting. 


\section{Professional Identities and Leadership}

Postmodernist perspectives view identities as multiple, complex, dynamic, tenuous and conflicting, in contrast to modernist conceptions of identity as distinct and stable. The process of constructing, deconstructing and re-constructing identity through discourse is based on the postmodern condition. The postmodern viewpoint on language, discourse, power and subjectivities assert our agency as cultural mediators that enact, propagate and to resist normative discourse and structures [16]-[18].

Educators may focus on achieving a greater understanding of children's social and cultural identities and the underlying complexities including the influences of local funds of knowledge [19], [20] and cultural capital [21] that helped to shape their identities (Ritchie,, 2005). Professional Identity construction and discourse has been seen to be tied up with concepts that include reflexivity, agency, performativity, knowledge, subjectivity and representation (Osgood, 2011b). Sumsion (2005) described her experience as an early childhood educator as one that entailed negotiating multiple roles and responsibilities within a workplace context that has become increasingly complex. The observation is that the modern early childhood teacher-practitioner-educator has to wear a number of hats and juggle roles that include learning facilitator, communicator, researcher( Edwards \& Gandini, 2015) and sometimes, an entrepreneur or business manager [25]. The tensions and congruence in the interconnections and relatedness of identity between professional and maternal discourses are also debated [26].

The development of leadership capacity within the early childhood education profession has been debated on in research literature. Research documenting professional growth and development has suggested that change is cyclical and non-linear [3] and this has also been supported by theoretical models representing the professional development cycle [27]. The modernist binary models of leaderfollower conceptions are not representative and reflective of contemporary scholarship and philosophy which describes identities as multiple, dynamic, negotiated and complex. While the modernist epistemology makes assumptions that the world is an integral dimension of an objective and rationally structured reality characterized by order and stability, postmodernist epistemology challenges the assumptions made by modernist philosophy. Postmodern perspectives on professional identities and leadership are dynamic, transforming and negotiated [28]. Leadership identities are not therefore characterized by static traits and leadership is viewed as non-linear in progression as compared to the modernist assumption that leadership is hierarchical and sequentially progressive. The expression of these professional identities is seen to be influenced by historical, sociocultural, political and institutional contexts and can change dynamically over a period [3]. The agency of self is also significant in influencing the construction of these identities by emphasizing various dimensions of themselves (as a mother, team member, advocate, colleagues etc.).

\section{Summary}

In conclusion, a postmodernist viewpoint can help to define or explain the dynamically changing curriculum and pedagogical practice that is subject to various domains of influence. It also allows us to view professional identities and educational leadership to be non-hierarchical, cyclical and subject to a continual change of constructing, deconstructing and re-constructing, tied to the processes of reflexivity, agency, performativity and representation. 
Conference: Kaleidoscopes 2021, $3^{\text {rd }}-4^{\text {th }}$ June (University of Cambridge, Faculty of Education)

Strand: Connecting Theory and Practice in Times of Change

\section{REFERENCES:}

[1] P. Slattery, "Introduction to Curriculum Development, Reconceptualization and Postmodernity.," in Curriculum development in the Postmodern Era: Teaching and learning in the age of accountability, Taylor \& Francis Group, 2012, pp. 17-36.

[2] M. Peters and C. Lankshear, "Curriculum in the postmodern condition," 2001.

[3] J. Nicholson and H. Maniates, "Recognizing postmodern intersectional identities in leadership for early childhood," Early Years, vol. 36, no. 1, pp. 66-80, 2016.

[4] R. Usher and R. Edwards, "Postmodernism, Postmodernity and the Postmodern Moment," in Postmodernism and Education, London \& New York: Routledge, 1994.

[5] R. Levy, “'Third spaces’ Are Interesting Places: Applying 'Third Space Theory’ to Nursery-Aged Children's Constructions of Themselves as Readers," J. Early Child. Lit., vol. 8, no. 1, pp. 43-66, 2008.

[6] Y.-S. Lin, “A Third Space for Dialogues on Creative Pedagogy: Where Hybridity Becomes Possible,” Think. Ski. Creat., vol. 13, no. 2, pp. 43-56, 2014.

[7] J. Ritchie, "Implementing Te Whàriki as Postmodernist Practice: A Perspective from Aotearoa/New Zealand," Adv. Early Educ. Day Care, vol. 14, no. 05, pp. 109-136, 2005.

[8] H. A. Giroux, C. Lankshear, P. McLaren, and M. Peters, Counter Narratives: Cultural studies and Critical Pedagogies in Postmodern Spaces. New York and London: Routledge, 1996.

[9] A. L. Goodwin, "Globalization and the preparation of quality teachers: Rethinking knowledge domains for teaching," Teach. Educ., vol. 21, no. 1, pp. 19-32, 2010.

[10] S. Ryan and S. Grieshaber, "Shifting from Developmental to Postmodern Practices in Early Childhood Teacher Education," vol. 56, no. 1, 2005.

[11] D. W. Chen, J. Nimmo, and H. Fraser, "Becoming a Culturally Responsive Early Childhood Educator," Multicult. Perspect., vol. 11, no. 2, pp. 101-106, 2009.

[12] M. Bauml and K. Mongan, "Getting to Know You: Sharing Time as Culturally Relevant Teaching," Dimens. Early Child., vol. 42, no. 2, pp. 4-11, 2014.

[13] T. C. Howard, "Culturally Relevant Pedagogy : Ingredients for Critical Teacher Reflection," Theory Pract., vol. 42, no. 3, pp. 195-202, 2003.

[14] M. M. Smith and T. Chao, "Critical Science and Mathematics Early Childhood Education: Theorizing Reggio, Play, and Critical Pedagogy into an Actionable Cycle," Educ. Sci., vol. 8, no. 4, p. 162, 2018.

[15] E. Maagero and B. Simonsen, "Constructing an Inclusive Culture in Kindergarten," in Cross-Cultural Perspectives on Early Childhood, T. Papatheodorou and J. Moyles, Eds. SAGE Publications, 2012, pp. 77-88.

[16] E. A. St. Pierre, “Another Postmodern Report on Knowledge: Positivism and Its Others," Int. J. Leadersh. Educ., vol. 15, no. 4, pp. 483-503, 2012.

[17] E. A. St. Pierre, "Poststructural Feminism in Education: An Overview," Int. J. Qual. Stud. Educ., vol. 13, no. 5, pp. 477-515, 2000.

[18] D. E. Foley, “Critical Ethnography : The Reflexive Turn,” Qual. Stud. Educ., vol. 15, no. 5, pp. 469-490, 2002.

[19] N. González, "Beyond Culture: The Hybridity of Funds of Knowledge," in Funds of Knowledge: Theorizing Practices in Households, Communities and Classrooms, N. Gonzalez, L. C. Moll, and C. Amanti, Eds. Lawrence Erlbaum Associates Inc, 2005.

[20] L. C. Moll et al., "Funds of Knowledge for Teaching: Using a Qualitative Approach to Connect Homes and Classrooms," Theory Pract., vol. 31, no. 2, pp. 132-141, 1992.

[21] K. Mikus, N. Tieben, and P. S. Schober, "Children's Conversion of Cultural Capital into Educational Success: the Symbolic and Skill-Generating Functions of Cultural Capital," Br. J. Sociol. Educ., vol. 41, no. 2, pp. 197-217, 2020.

[22] J. Osgood, Narratives from the Nursery: Negotiating Professional Identities in Early Childhood. London: Routledge, 2011.

[23] J. Sumsion, "Putting Postmodern Theories into Practice in Early Childhood Teacher Education," Adv. Early Educ. Day Care, vol. 14, no. 05, pp. 193-216, 2005. 
Conference: Kaleidoscopes 2021, $3^{\text {rd }}-4^{\text {th }}$ June (University of Cambridge, Faculty of Education)

Strand: Connecting Theory and Practice in Times of Change

[24] C. P. Edwards and L. Gandini, "Teacher Research in Reggio Emilia, Italy: Essence of a Dynamic, Evolving Role.," Fac. Publ. Dep. Child, Youth Fam. Stud., p. https://digitalcommons.unl.edu/famconfacpub/105, 2015.

[25] O. Kamenarac, "Business Managers in Children's Playground : Exploring a Problematic (or not!) Identity Construction of Early Childhood Teachers in New Zealand," Contemp. Issues Early Child., 2021.

[26] J. Osgood, "Maternal Discourses and the Formation of Professional Identities.," in Narratives from the Nursery: Negotiating Professional Identities in Early Childhood, London: Routledge, 2011.

[27] D. Clarke and H. Hollingsworth, "Elaborating a Model of Teacher Professional Growth," Teach. Teach. Educ., vol. 18, pp. 947-967, 2002.

[28] R. Frie, "Identity, narrative, and lived experience after postmodernity: Between multiplicity and continuity," $J$. Phenomenol. Psychol., vol. 42, no. 1, pp. 46-60, 2011. 


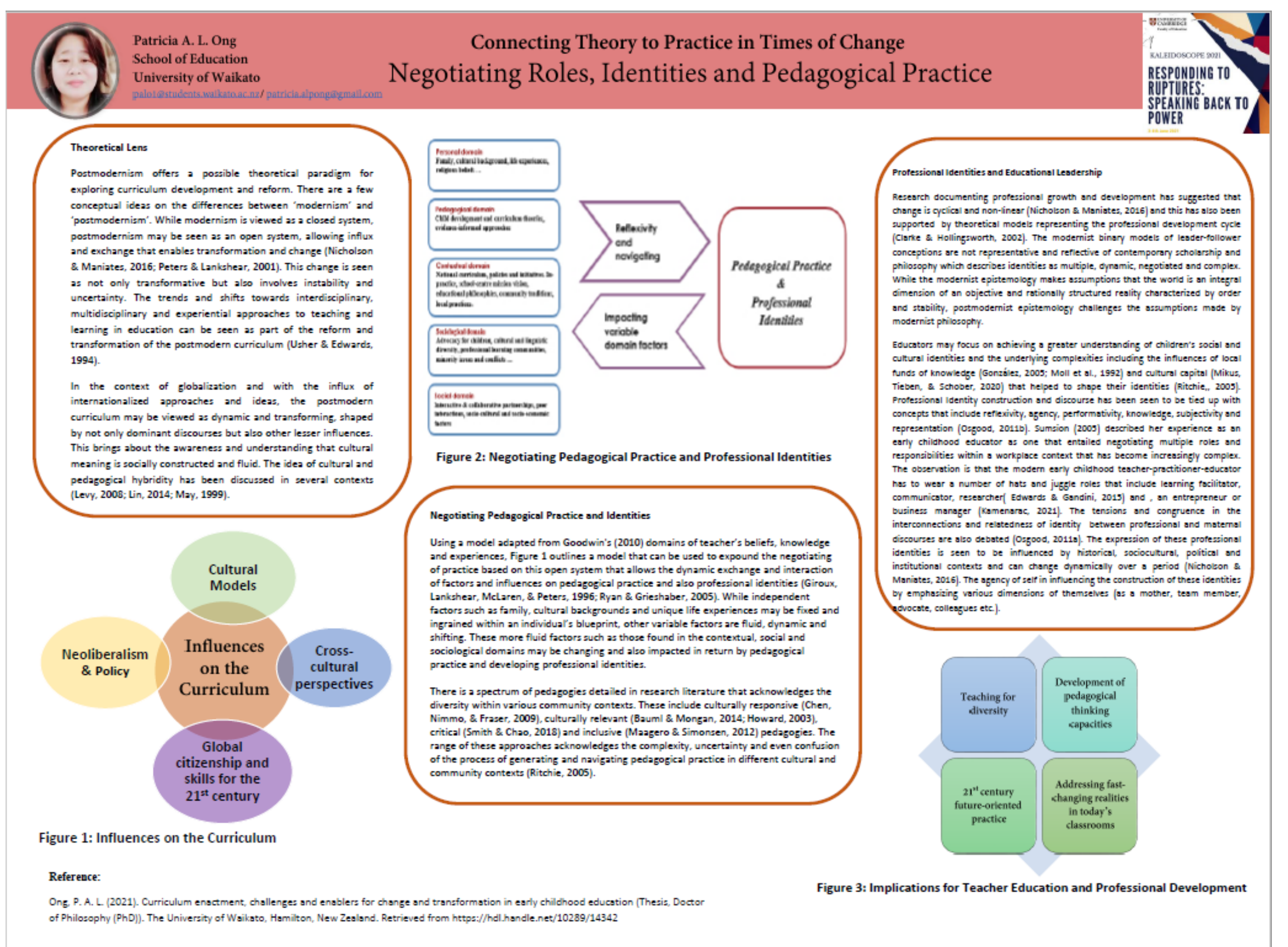

